\title{
Avaliação de impactos ambientais: urbanização do Açude de Bodocongó, Campina Grande/PB
}

O desenvolvimento urbano tem ocasionado o aumento das atividades antrópicas sobre os recursos naturais, gerando impactos negativos significativos ao meio ambiente. Nesta perspectiva, este estudo teve o objetivo de avaliar os impactos ambientais decorrentes da urbanização do Açude de Bodocongó, em Campina Grande, Paraíba, Brasil. Para análise desses impactos, adotou-se como instrumento de pesquisa: visitas in loco, através das quais foram aplicadas entrevistas não estruturadas com a população que circula o empreendimento, observação direta e registros fotográficos. Os impactos foram identificados e descritos através de checklist e avaliados por meio de matriz. Constatou-se que a urbanização resultou em seis impactos positivos e nove negativos. Entre os impactos positivos destacam-se mudança da paisagem e a construção do Parque Ecológico de Bodocongó, cujo principal efeito compreendeu a reorganização econômica e social daquela área, contribuindo para o desenvolvimento de novos tecidos urbanos e valorização local. Os impactos negativos identificados, porém, expressam maior magnitude e ameaçam a estabilidade daquele sistema aquático que constitui um patrimônio histórico, considerado pelos cientistas como berço da Limnologia. Observou-se a desconstrução da figura cênica típica da região e a intensificação dos impactos negativos que vem provocando a degradação daquele sistema aquático ao longo dos anos. No caso, de persistir a degradação, o Açude de Bodocongó tornar-se-á apenas uma página da história.

Palavras-chave: Meio ambiente; Urbanização; Recurso hídrico; Gestão ambiental.

\section{Environmental impact assessment: urbanization of the Bodocongó Reservoir, Campina Grande/PB}

\begin{abstract}
Urban development has caused an increase in human activities on natural resources, generating significant negative impacts on the environment. In this perspective, this study had the objective of evaluating the environmental impacts resulting from the urbanization of the Bodocongó's water reservoir, in Campina Grande, Paraíba, Brazil, which alter the local landscape. For the analysis of the impacts, it was adopted as a research tool: on-site visits, through which applied unstructured interviews were made with the population that hangs around the enterprise, direct observation, and photographic records. The impacts were identified and described through the checklist and evaluated by matrix. It was verified that the urbanization resulted in six positive and nine negative impacts. Among the positive impacts highlighted the changing landscape and the construction of the Ecological Park of Bodocongó, whose main effect included the economic and social reorganization of the area, contributing to the development of new urban fabrics and local valorization. Among the negative impacts identified, however, they express greater magnitude and threaten the stability of that aquatic system which constitutes a historical patrimony, considered by scientists as the cradle of Limnology. It was observed the deconstruction of the typical scenic figure of the region was observed and the intensification of the negative impacts that have caused the degradation of that aquatic system over the years. In case, if degradation persists, the Bodocongó's water reservoir it will become just a page of history.
\end{abstract}

Keywords: Environment; Urbanization; Water resource; Environmental management.

Topic: Planejamento Urbano

Reviewed anonymously in the process of blind peer.
Received: 02/12/2020

Approved: $24 / 12 / 2020$
Elaine Cristina dos Santos Araújo î

Universidade Estadual da Paraíba, Brasil http://lattes.cnpq.br/1224773257521776 http://orcid.org/0000-0002-6288-8469 crys lainne@yahoo.com.br

Ivanise Gomes (iD

Universidade Estadual da Paraíba, Brasil http://lattes.cnpq.br/6042837219372011 http://orcid.org/0000-0003-4561-8739

ivanisegomesbio@gmail.com

Monica Maria Pereira Silva (iD)

Universidade Estadual da Paraíba, Brasil http://lattes.cnpq.br/8972860324282858 http://orcid.org/0000-0002-1593-1698 monicaea@terra.com.br

\section{Referencing this:}

ARAÚJO, E. C. S.; GOMES, I.; SILVA, M. M. P.. Avaliação de impactos ambientais: urbanização do Açude de Bodocongó, Campina Grande/PB. Revista Ibero Americana de Ciências Ambientais, v.11, n.7, p.787-797, 2020. DOI: http://doi.org/10.6008/CBPC21796858.2020 .007 .0060

DOI: 10.6008/CBPC2179-6858.2020.007.0060 


\section{INTRODUÇÃO}

Acredita-se que o planeta Terra tem 4,6 bilhões de anos. Durante as últimas frações de segundo geológico da história do nosso planeta, a espécie Homo sapiens interferiu em ciclos naturais, interagindo dinamicamente para formar as atuais condições de vida que conhecemos e para as quais nos adaptamos (BRÜGGER, 1999).

As modificações provocadas por ações humanas em sistemas urbanos têm provocado a destruição de áreas com grande importância ambiental, especialmente em bacias hidrográficas (DAMAME et al., 2019).

Por trás das diferentes semânticas, baseada nos conceitos, preconceitos, culturas e paradigmas, o meio ambiente é moldado conforme o discernimento do ser humano, que quase sempre remete a um cenário de degradação ambiental. Não há devida preocupação com as gerações futuras e, vários problemas são gerados, ameaçando a continuidade da vida no Planeta Terra (MACHADO, 1999; SILVA et al., 2000; 2001; 2002; SILVA, 2020). A cultura da população de uma região reflete não apenas nos costumes e hábitos de consumo, influenciam também diretamente no meio ambiente, impactando-o (ANTONI et al., 2013).

Procurando compreender o termo impacto ambiental, haja vista que a literatura técnica apresenta divergências, encontramos alguns conceitos como forma de nortear e embasar as discussões ora propostas. Nesse entendimento, a Resolução do CONAMA (Conselho Nacional do Meio Ambiente) n001 de 1986, considera impacto ambiental qualquer alteração das propriedades físicas, químicas e biológicas do meio ambiente, provocadas por interferências antrópicas que de forma direta ou indireta gerem modificações à saúde, à segurança, ao bem-estar da população, às atividades socioeconômicas e aos seres vivos, pondo em risco a qualidade ambiental (BRASIL, 1986).

Segundo Coelho (2004) impacto ambiental constitui um processo de mudanças sociais e ecológicas causado por perturbações ambientais. Diz respeito ainda, de acordo com a autora, com a relação entre sociedade e natureza que se transforma diferencial e dinamicamente. Os impactos ambientais são descritos no tempo e incidem diferentemente, alterando as estruturas das classes sociais e reestruturando o espaço. Para Sánchez (2008) impacto ambiental é qualquer alteração positiva ou negativa sobre o meio ambiente, provocada por ações humanas num determinado local, que resulte na modificação de processos naturais ou sociais.

À luz de todas essas considerações, impacto ambiental é claramente o resultado das ações antrópicas, estando cada vez mais evidenciado na sociedade contemporânea. Na medida em que os processos de exploração e apropriação dos recursos naturais se intensificam, observam-se alterações nas dinâmicas econômicas, culturais, históricas, ambientais, sociais e políticas.

Essa é uma das razões pela qual, nos últimos anos, os ambientes aquáticos vêm sendo explorados de maneira irracional e considerados como inesgotáveis, comprometendo a recuperação natural do sistema e o uso futuro.

Os impactos sobre os sistemas aquáticos acarretam consequências diretas à qualidade da água superficial e subterrânea, aumentam as probabilidades de afetar a saúde humana, notadamente por doenças 
de veiculação hídrica, diminuem a quantidade de água disponível, majoram os custos da produção de alimentos e do tratamento de água, constituindo-se entrave ao desenvolvimento industrial e agrícola (CARVALHO, 2007) e à melhoria da qualidade de vida.

Os recursos hídricos configuram-se um dos temas que expressa preocupação e debates entre diferentes atores sociais, uma vez que, quando não são manejados de forma eficiente, pode ocasionar impactos negativos significativos à vida diária das pessoas, à economia regional e nacional, à saúde humana e ambiental (ANDRADE et al., 2018). A ocupação urbana é responsável implicitamente pelas alterações adversas sofridas nas áreas de bacias hidrográficas que afetam a interação entre os fragmentos florestais, impedindo os ciclos dos nutrientes (DAMAME et al., 2019), consequentemente, dificultando a homeostase do sistema.

Em Campina Grande, estado da Paraíba, no início de 1917 (103 anos) foi construído o Açude de Bodocongó no intuito de atenuar a escassez de água na região, uma vez que os reservatórios existentes não estavam suprindo a demanda da população. O nível elevado de salinidade impossibilitou o uso doméstico. No entanto, o açude passou a ser explorado para várias outras atividades (COSTA, 2011). Dentre elas, a utilização ao longo dos anos, como local de lazer, irrigação, pesca amadora, dessedentação de animais, local de descarga de águas pluviais, lavagem de veículos e de roupa, práticas esportivas, manutenção do clima e harmonia paisagística (CARVALHO, 2007). Também serviu de base para o desenvolvimento industrial e residencial da região e foi palco do primeiro estudo de Limnologia, seguindo-se com várias outras pesquisas limnológicas de nível nacionais e internacionais, como cita Esteves (1998).

O Açude de Bodocongó é considerado um marco cultural e histórico da região, sendo fruto de grandes canções, como Bodocongó, interpretado por grandes cantores da música brasileira, Luiz Gonzaga e Elba Ramalho. Contudo, este patrimônio imaterial, ao longo das décadas, vem sendo degradado, em consequência do manejo impróprio dos múltiplos usos da água e ocupação desordenada no entorno do açude, o que tem contribuído para diminuição considerável do seu volume e aumento do quadro de poluição e contaminação de suas águas.

Atualmente, o Açude de Bodocongó passou por um processo de construção do então chamado Parque Ecológico de Bodocongó. O empreendimento prometeu proporcionar à população um local de convergência de atividades de cultura e lazer, seguindo os princípios da sustentabilidade, preservação histórica e ambiental.

A implementação de um ou conjunto de ações que tenha potencial de causar impactos ambientais significativos que afetam, degradam ou consomem recursos naturais que pertencem à coletividade, deve ser precedida de uma avaliação de impacto ambiental, através do qual é possível identificar, interpretar e comunicar informações, no sentido de confirmar a identificação preliminar e para a previsão da magnitude dos impactos no meio físico, biótico e antrópico no local (SÁNCHEZ, 2008).

Nessa perspectiva, este estudo tem como objetivo avaliar os impactos ambientais decorrentes da urbanização do Açude de Bodocongó, situado em Campina Grande, Paraíba, Brasil. 


\section{METODOLOGIA}

O estudo foi realizado na cidade de Campina Grande, no planalto da Borborema. A cidade situa-se no semiárido nordestino, na mesorregião do agreste paraibano, com altitude de $550 \mathrm{~m}$ acima da superfície do mar e com ocupação geográfica de $593.026 \mathrm{~km}^{2}$. Apresenta uma população estimada de 409.731 mil habitantes, podendo chegar a uma população flutuante de 600 mil habitantes (IBGE, 2019).

O bairro de Bodocongó localiza-se na porção central da cidade de Campina Grande, que originalmente deu o nome ao açude ( $\left.7^{\circ} 12^{\prime} 49.0^{\prime \prime} \mathrm{S} 35^{\circ} 54^{\prime} 53.0^{\prime \prime} \mathrm{W}\right)$. O Açude de Bodocongó é um dos afluentes da bacia hidrográfica do Rio Paraíba, com capacidade máxima de $1.020 .000 \mathrm{~m}^{3}$ (FIGURA 1). 0 clima da região, conforme a classificação climática de Köppen é do tipo $\mathrm{Bs}$ 'h com temperatura variando entre $22^{\circ} \mathrm{C}$ e $26^{\circ} \mathrm{C}$. $\mathrm{O}$ período chuvoso ocorre entre outono e inverno e a precipitação pluviométrica é em torno de 700 mm anuais (CPRM, 2005).

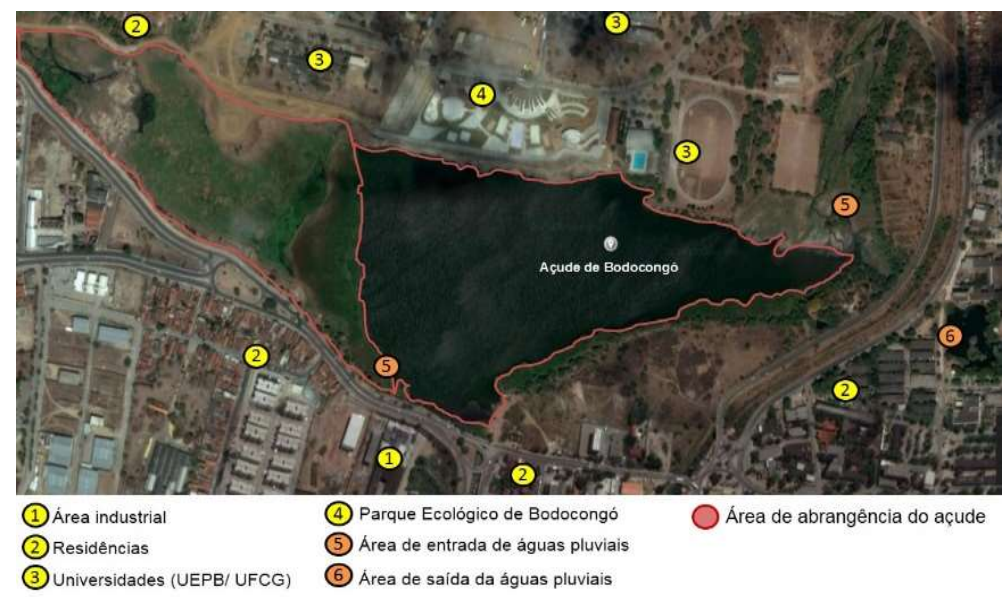

Figura 1: Vista aérea do Açude de Bodocongó e suas intermediações. Fonte: Google Maps adaptado.

Adotou-se como instrumentos de pesquisa: visitas in loco, através das quais foram aplicadas entrevistas não estruturadas com a população que circula no entorno do empreendimento, observação direta e registros fotográficos.

Os resultados foram identificados e descritivos através de checklist e avaliados por meio de matriz. Foram considerados os impactos de âmbitos bióticos, físicos, antrópicos, estéticos, culturais, econômicos e sociais da urbanização da área estudada e as suas respectivas características: modalidade (positivo ou negativo); efeito (direto ou indireto); abrangência (local ou regional); Previsão (curto, médio ou longo); Grau (baixo, moderado e grave); Dimensão (ambiental, econômico e social) e reversibilidade (reversível e irreversível).

A aplicação da listagem descritiva, denominada por Rocha (1997) de Checklist contribuiu para identificar as atividades e os respectivos impactos ambientais na área de influência direta e indireta da construção do empreendimento instalado no entorno do Açude de Bodocongó.

\section{RESULTADOS E DISCUSSÃO}

Constatou-se que a urbanização resultou em 15 impactos, prevalecendo os impactos negativos 
(60\%). Entre os impactos positivos, destacou-se a mudança da paisagem, construção do Parque Ecológico de Bodocongó, cujo principal efeito compreendeu a reorganização econômica e social, contribuindo para o desenvolvimento de novos tecidos urbanos e valorização local. Os impactos negativos identificados, porém, expressam maior magnitude e ameaçam a estabilidade daquele sistema aquático que constitui um patrimônio histórico, considerado pelos cientistas como berço da Limnologia (Quadro 1).

Quadro 1: Impactos ambientais provocados pela urbanização do Açude de Bodocongó. Campina Grande-PB.

\begin{tabular}{|c|c|c|c|c|c|c|c|c|c|c|c|c|c|c|c|c|c|c|}
\hline \multirow{2}{*}{\multicolumn{2}{|c|}{ Tipo de impacto }} & \multicolumn{2}{|c|}{$\begin{array}{l}\frac{\pi}{8} \\
\frac{\pi}{0} \\
\frac{0}{\pi} \\
\frac{\pi}{8} \\
\frac{1}{2} \\
\sum\end{array}$} & \multicolumn{2}{|c|}{ 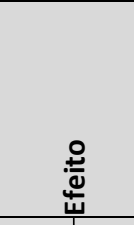 } & \multicolumn{2}{|c|}{ 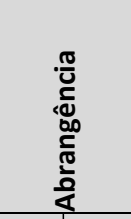 } & \multicolumn{3}{|c|}{ 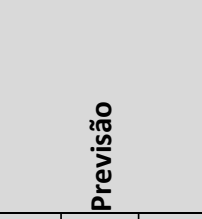 } & \multicolumn{3}{|c|}{ ป⿱艹 } & \multicolumn{3}{|c|}{ 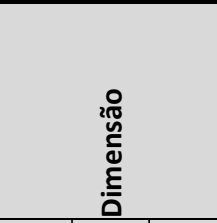 } & \multicolumn{2}{|c|}{ 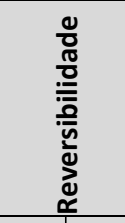 } \\
\hline & & 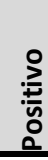 & 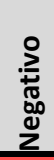 & $\begin{array}{l}\stackrel{8}{0} \\
\stackrel{0}{\circ}\end{array}$ & $\begin{array}{l}\stackrel{ }{0} \\
\stackrel{\underline{\nu}}{\circ} \\
\text { 으 } \\
\end{array}$ & త్ర్త & $\begin{array}{l}\bar{\pi} \\
\stackrel{0}{0} \\
\stackrel{0}{00} \\
\stackrel{0}{\simeq} \\
\end{array}$ & 욜 & $\begin{array}{l}\frac{0}{8} \\
\stackrel{0}{\mathbb{d}}\end{array}$ & $\begin{array}{l}0 \\
\text { o. } \\
0 \\
0 \\
\end{array}$ & 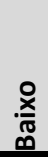 & $\begin{array}{l}\frac{0}{0} \\
\frac{\pi}{0} \\
\frac{\pi}{0} \\
\Sigma\end{array}$ & 䒕 & 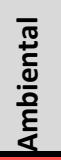 & 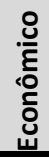 & $\begin{array}{l}\overline{\frac{\pi}{4}} \\
\text { ஜ }\end{array}$ & 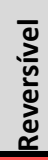 & 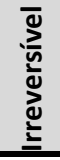 \\
\hline \multirow{3}{*}{ 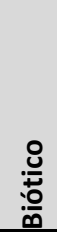 } & Desmatamento & & $x$ & $x$ & & $x$ & & & $x$ & & & $x$ & & $x$ & & & $x$ & \\
\hline & $\begin{array}{l}\text { Redução da } \\
\text { biodiversidade }\end{array}$ & & $x$ & $x$ & & $x$ & & & & $x$ & & & $x$ & $x$ & & & $x$ & \\
\hline & Eutrofização & & $x$ & $x$ & & $x$ & & & $x$ & & & & $x$ & $x$ & & & $x$ & \\
\hline \multirow{4}{*}{$\frac{80}{\frac{0}{4}}$} & $\begin{array}{l}\text { Impermeabilizaçã } \\
\text { o do solo }\end{array}$ & & $x$ & $x$ & & $x$ & & & & $x$ & & & $x$ & $x$ & & & & $x$ \\
\hline & Esgoto sanitário & & $x$ & $x$ & & $\mathrm{x}$ & & $x$ & & & & $x$ & & $x$ & & & $x$ & \\
\hline & Assoreamento & & $x$ & $x$ & & $\mathrm{x}$ & & & & $x$ & & $x$ & & $x$ & & & $x$ & \\
\hline & Ilhas de calor & & $x$ & & $x$ & & $x$ & & & $x$ & & $x$ & & $x$ & & & $x$ & \\
\hline \multirow{2}{*}{$\begin{array}{l}\frac{.0}{0} \\
\frac{0}{0} \\
\frac{1}{2}\end{array}$} & Infraestrutura & $x$ & & $x$ & & $x$ & & & & $x$ & $x$ & & & & & $x$ & $x$ & \\
\hline & Segurança & $x$ & & $x$ & & $x$ & & & & $x$ & $x$ & & & & & $x$ & $x$ & \\
\hline \multirow{2}{*}{ 苟 } & Paisagem urbana & $x$ & & $x$ & & $x$ & & & & $x$ & $x$ & & & & & $x$ & $x$ & \\
\hline & Paisagem natural & & $x$ & $x$ & & $x$ & & $x$ & & & & $x$ & & $x$ & & & $x$ & \\
\hline $\begin{array}{l}\overline{0} \\
\frac{2}{3} \\
\frac{ \pm}{3}\end{array}$ & $\begin{array}{l}\text { Patrimônio } \\
\text { histórico }\end{array}$ & & $x$ & & $x$ & & $x$ & & & $x$ & $x$ & & & & & $x$ & $\mathrm{x}$ & \\
\hline 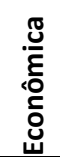 & $\begin{array}{l}\text { Geração de } \\
\text { emprego e renda }\end{array}$ & $x$ & & & $x$ & $x$ & & & & $x$ & $x$ & & & & $x$ & & $x$ & \\
\hline \multirow{2}{*}{ 吾 } & $\begin{array}{l}\text { Valorização } \\
\text { imobiliária }\end{array}$ & $x$ & & & $x$ & $x$ & & & & $x$ & $x$ & & & & & $x$ & $x$ & \\
\hline & Saúde & $x$ & & & $x$ & $x$ & & & $x$ & & $x$ & & & & $x$ & & $x$ & \\
\hline
\end{tabular}

Legenda: Verde: impacto positivo; Vermelha: impacto negativo.

\section{Ao meio biótico}

A avaliação ambiental das alterações decorrentes da urbanização no entorno do Açude de Bodocongó, constatou a supressão da mata ciliar em grande parte das margens do açude e a substituição 
por áreas de concreto. Esse processo segue contrário às tentativas de minimizar o déficit de 700 mil árvores no município de Campina Grande, bem como ao que preconiza a Lei 12.651 do código florestal que garante uma área de preservação permanente da vegetação nativa de no mínimo 30 metros (BRASIL, 2012).

As nascentes que alimentam o Açude de Bodocongó estão completamente desprovidas de vegetação. Na maior área de drenagem não existe mata ciliar, acarretando o seu assoreamento e comprometendo o aporte hídrico e consequente diminuição do espelho d'água. Fato já observado por Moraes Neto et al. (2016), porém, atualmente em maior proporção.

Segundo Guedes Filho et al. (2012), na área de estudo, era possível encontrar exemplares de espécies de plantas típicas da região, tais como, jurema preta (Mimosa tenuiflora Wild. Poiret), juazeiro (Zizyphus joazeiro Mart), catingueira (Caesalpinia vulgares), umbuzeiro (Spondias tuberosa) e marmeleiro (Cydonia oblonga). Além disso, modificou o habitat de espécies da fauna, a exemplo das aves garça vaqueira (Bubulcus íbis), lavadeira (Fuvicola nengeta) e rolinha roxa (Columbia talpacoti), frequentemente encontradas no local de estudo.

É importante destacar que a retirada da vegetação nativa no entorno do açude se deu para construção de áreas para atividades de lazer, recreação, usos para alimentação e eventos culturais, tornando, portanto, uma estratégia para promover a socialização e o convívio da população circunvizinha. No entanto, a retirada da mata nativa adjacente e a substituição por espécies exóticas, a exemplo de gramíneas ornamentais e palmeiras imperiais, contribuem para intensificação de processos erosivos e de assoreamento, minimização da biodiversidade vegetal, perda e alteração de habitats, mudanças de hábitos e de cadeias alimentares, influenciando negativamente sobre os elementos que compõem a sua paisagem natural ou predominantemente natural.

Sobre a população humana, a retirada da vegetação contribui para descaracterização da figura cênica típica da região do agreste, promovendo desconforto térmico na área de abrangência direta e indireta, incidindo na qualidade de vida, fazendo-se questionar a maneira como ocorre a urbanização entre as cidades brasileiras.

O desmatamento foi considerado uma ação reversível; há a necessidade da criação de áreas de preservação e/ou de conservação da mata remanescente na área de estudo, pois conforme citam Melo et al. (2012) e Silva et al. (2013) a mitigação da cobertura vegetal intensifica a exposição à radiação solar, promovendo o aumento da evapotranspiração e do déficit entre o balanço de captação e perda de água, desencadeando a mudança de microclimas locais, maior oxidação de matéria orgânica e redução da capacidade de retenção de água no solo.

\section{Ao meio físico}

O artigo $4^{\circ}$ da Lei Federal $n^{\circ} 6.766 / 79$ que dispõe sobre o parcelamento de solo urbano, alterado pela Lei Federal $n^{\circ}$ 10.932/04, determina a obrigatoriedade de uma área não-edificável de 15 metros em ambos os lados, ao longo das águas correntes e dormentes e das faixas de domínio público das rodovias e ferrovias (BRASIL, 2004). Observou-se por sua vez, que na prática a Lei não se aplica, uma vez que, foi realizado o 
aterramento de grande parte do açude, provocando o assoreamento do mesmo.

A área de preservação permanente do açude é atualmente composta por residências, condomínios, indústrias, hospitais, escolas, órgãos públicos, a exemplo de duas universidades públicas, uma federal e outra estadual e o então empreendimento Parque Ecológico de Bodocongó. Duas áreas são destinadas para a entrada e saída das águas pluviais que constantemente são utilizadas para despejos clandestinos de esgotos domésticos e industriais.

A construção do empreendimento Parque Ecológico de Bodocongó aumentou o processo de assoreamento, haja vista que grande área da obra foi construída dentro do açude, influenciando na dinâmica e no curso das águas no período de maior volume, contribuindo para possíveis inundações, perdas dos usos múltiplos da água, descaracterização da topográfica, alagamentos de áreas marginais em virtude do desvio do fluxo de águas pluviais que dependerá muito da vulnerabilidade física do local e do sistema de drenagem. Tais impactos também foram identificados por Costa (2011), Ferreira et al. (2014) e Andrade et al. (2018).

Vale ressaltar que as mediações do departamento de educação física de uma das universidades estão instaladas às margens do açude. Com o aterramento de parte do açude para construção do parque, o departamento ficou no nível consideravelmente mais baixo que a área do parque, sendo potencial local de alagamento durante chuvas fortes.

O assoreamento é uma das atividades que têm comprometido a infraestrutura do Açude de Bodocongó, promovendo a redução do volume acumulado e, por conseguinte, a vazão do açude. Além disso, tem contribuído para elevação da turbidez e danos à biodiversidade com o araste e aterramento de parte do açude (GUEDES FILHO et al., 2012).

O estudo de geoprocessamento e processamento de imagens realizada por Moraes Neto et al. (2016) identificou que a área ao longo da bacia hidrográfica encontra-se altamente degradada, devido as ações antrópicas, promovendo o assoreamento do açude, o que tem comprometido seu volume hídrico e reduzindo o espelho d'água cerca em $32,87 \%$ nos últimos anos.

Um plano de dragagem do açude foi prometido no início das obras do Parque Ecológico de Bodocongó, juntamente ao plano de saneamento, coleta seletiva e educação ambiental. Projeto esses, que, inexplicavelmente, não foram cumpridos.

Esse quadro é resultado da carga de materiais poluentes oriundo do descarte irregular de resíduos sólidos urbanos e efluentes domésticos e industriais. Vislumbra-se um notório processo de eutrofização das águas, que confere a cobertura da lamina d'água de plantas macrófitas, indicadoras do grau de poluição.

No entendimento de Guedes Filho et al. (2012), o processo de eutrofização do açude ocorre devido a quantidade excessiva de resíduos incorporados a água, principalmente os resíduos líquidos in natura (esgoto bruto) que resulta na diminuição de organismos responsáveis pela aeração da água e consequentemente, redução da biodiversidade local. Andrade et al. (2018) ao estudarem a qualidade das águas do Açude de Bodocongó por meio dos parâmetros oxigênio dissolvido, condutividade elétrica e sólidos totais, ratificaram a contaminação de suas águas e atribuíram às ações antrópicas através de lançamento de efluentes e resíduos sólidos e lavagem de veículos às suas margens. 
As galerias de drenagem urbana são utilizadas há anos de forma clandestina para descarga de esgotos industriais e domésticos para área de abrangência do Açude de Bodocongó. Para Costa (2011) o lançamento de esgoto bruto no açude, constitui um risco potencial à qualidade das águas, a exemplo da redução dos teores de oxigênio dissolvido, exalação de odores, proliferação de vírus, bactérias e protozoários, resultando na contaminação de animais e seres humanos, através do consumo ou contato direto com a água.

A análise feita em quatro pontos amostrais do açude, Carvalho et al. (2009), revelaram que o nível de coliformes fecais é superior a 1000 UFC/100 mL em 100\% das amostras avaliadas, permitindo classificar as águas como imprópria para a recreação de todos os tipos, segundo resolução CONAMA n 274 de 2000 , para fim de balneabilidade (BRASIL, 2000).

Os elevados índices de coliformes fecais representam riscos à saúde da população da Vila dos Teimosos que reside no entorno do açude, visto que é prática comum, flagra de moradores utilizarem as águas para fins recreativos. As observações in loco apontam que o Açude de Bodocongó persiste recebendo descarga de esgoto bruto industrial e doméstico e de resíduos sólidos, atualmente, em maior quantidade, devido à expansão urbana naquela área. Expressando a ausência de efetivação das Políticas Públicas e a omissão dos poderes públicos e da sociedade civil organizada.

O estado da Paraíba apresenta um quadro de escassez das águas, embora já esteja recebendo água oriunda da transposição das águas do Rio São Francisco em alguns municípios. Nessa perspectiva, a falta de cuidado com os recursos hídricos continua a ser um fator preponderante na região. Isso ocorre em virtude da falta de sensibilização da população, do Poder Público e setor privado. Há escassez de projetos de Educação Ambiental voltados para aquele importante e histórico sistema aquático.

Por ser um bem de domínio público, a preservação da qualidade das águas deve ser de responsabilidade compartilhada por todos. Vislumbra-se, por sua vez, que a materialização do Direito não depende apenas de textos normativos, mas da participação popular. O conhecimento e o empoderamento desse direito devem ser praticados.

\section{Ao meio antrópico}

Verifica-se a utilização de práticas como a lavagem de carros e caminhões de forma clandestina. Essa atividade constitui uma prática potencialmente poluidora, constituindo um risco à saúde dos lavadores e proprietários. De acordo com Guedes Filho et al. (2012), esse uso, da forma como vem sendo desenvolvido, resulta na degradação da qualidade da água provocada por óleos e graxas proveniente da lavagem dos veículos. Não se pode negar que a urbanização promoveu a melhoria da infraestrutura, segurança, valorização da área e paisagismo, contribuindo para redução dos usos inadequados das águas do açude, promoveu a socialização da população com espaços esportivos, de lazer e cultural.

As atuais tentativas de salvar o Açude de Bodocongó, a partir da construção do Parque Ecológico de Bodocongó, primariamente descrita nos meios de comunicação como projeto de revitalização do açude, não alcançaram seus objetivos na prática. Na verdade, todas as atividades realizadas no seu entorno, nada mais é do que um contínuo processo de urbanização, que, aliado à falta de consciência da população campinense, 
ausência de fiscalização e a apatia do Poder Público promoverá, em curto prazo, a intensificação dos impactos negativos sobre o açude. As provas concretas estão expressas na degradação dos cursos d'água em áreas urbanizadas, a exemplo do Rio Tietê, Rio Paraíba, Açude de Boqueirão, Açude Velho, Açude Novo, entre outros.

O empreendimento cumpriu o prometido que era a transformação da paisagem local. Transformou um patrimônio histórico imaterial em um local atraente para os turistas tirarem fotos, enquanto camufla a ausência de saneamento básico e a gestão inadequada de resíduos sólidos. A falta de cuidado com a qualidade da água aumenta o quadro de degradação ambiental que o açude já vinha sofrendo, ao longo dos anos, em virtude das ações antrópicas.

Além disso, o empreendimento de urbanização do Açude de Bodocongó não apresenta relatório de impacto ambiental (RIMA). Se tiver, não é acessível ao público, situação essa que vem se repetindo nos empreendimentos do estado. Esse fato foi constatado na dificuldade em conseguir autorização para acesso dos pesquisadores à obra e aos documentos para o licenciamento do empreendimento. E nas ameaças veladas aos pesquisadores nas tentativas dos registros fotográficos. Afinal, por ser um empreendimento de cunho público e a própria resolução determina a obrigatoriedade de audiência pública para informar e consultar a população sobre o projeto e os possíveis impactos ambientais detalhados no RIMA. Caso estivesse regulamentado conforme as diretrizes, então, não haveriam a necessidade de camuflar informações.

De acordo com o Conselho Nacional do Meio Ambiente, o CONAMA, sob resolução n001 de 1986, qualquer projeto urbanístico de considerável interesse ambiental deve realizar estudo de impacto ambiental e respectivo relatório de impacto ambiental a serem submetidos à aprovação dos órgãos competentes (BRASIL, 1986). A própria Lei complementar municipal de Campina Grande de $n^{\circ} 042$ (CAMPINA GRANDE, 2009), torna obrigatória a realização do estudo de impacto ambiental e relatório de impacto ambiental para qualquer obra ou atividade potencialmente poluidora que possam causar significativa degradação ambiental.

Sánchez (2008) aborda que o relatório de impacto ambiental deve estar de forma acessível e de fácil entendimento para o debate e participação popular. Isso decorre em virtude de que os empreendimentos que tem potencial de causar impactos significativos usualmente degradam, afetam ou consomem os recursos naturais que dizem respeito a todos e, portanto, sua instalação requer a decisão da pública. Dessa forma, a consulta pública é uma das etapas mais importantes do processo de avaliação de impacto ambiental, o que não foi realizado no empreendimento instalado no Açude de Bodocongó.

A população envolvida no empreendimento aponta o descaso com a opinião pública. Reconhece que o saneamento básico deveria ser prioridade pelos governantes: 'seria mais interessante se o governo investisse em obras como o saneamento básico da área para evitar que o esgoto escoasse para o açude' (morador 1). Verificou-se, porém, que a construção do empreendimento não apresenta iniciativas voltadas para mitigar o lançamento de efluentes no açude, tais como, medidas de fiscalização a serem efetuadas por órgãos ambientais de forma a avaliar se os efluentes lançados estão dentro dos padrões permitidos por Lei.

O Açude de Bodocongó apresenta condições precárias de manutenção, conforme comprovado a partir do depoimento de outro morador: 'o açude está doente, ele pede socorro e tem que ser tratado' 
(morador 2). Há falta de cuidado, por parte dos gestores públicos e da população. A comunidade local usa as águas como bem desejam, lavando caminhões, jogando detritos e ocupando desordenadamente as margens do entorno, sem o devido cuidado com a sustentabilidade do mesmo. Se a degradação ambiental continuar, o açude tornará apenas página da história da cidade. É fundamental a adoção de medidas para mitigar o quadro de impactos socioambientais negativos.

Antes o exposto, verifica-se que a legislação ambiental brasileira mostra tímidas e distantes modificações da realidade na prática. Por isso, torna-se premente o conhecimento e a materialização do direto, a participação popular e o espírito comunitário. A Educação Ambiental apresenta-se, nesse viés, enquanto um importante instrumento, por estimular mudanças de percepção e atitudes em relação ao meio ambiente em que vive o ser humano.

\section{CONCLUSÕES}

A urbanização do Açude de Bodocongó, em Campina Grande, Paraíba, Brasil, resultou em seis impactos positivos e nove negativos. Entre os impactos positivos, sobressaem a mudança da paisagem, a construção do Parque Ecológico de Bodocongó, cujo principal efeito compreendeu a reorganização econômica e social, contribuindo para o desenvolvimento de novos tecidos urbanos e valorização local. Os impactos negativos identificados, porém, expressam maior magnitude e ameaçam a estabilidade daquele sistema aquático que constitui um patrimônio histórico, considerado pelos cientistas como berço da Limnologia.

A urbanização da área do entorno do Açude de Bodocongó gerou alteração da qualidade ambiental, contribuindo para intensificar os problemas existentes e originar novos problemas. $\mathrm{O}$ descarte inadequado de resíduos sólidos, a destinação de efluentes domésticos e industriais sem tratamento, a lavagem clandestina de veículos, a compactação e impermeabilização do solo, o assoreamento, a ampliação da supressão da mata ciliar e a perda da biodiversidade de espécies da fauna e flora do bioma caatinga, são os principais problemas identificados na área estudada.

Observou-se a desconstrução da figura cênica típica da região e a intensificação dos impactos negativos que vem agravando e acelerando a degradação daquele sistema aquático. A recuperação do Açude de Bodocongó é uma necessidade sentida na esfera ambiental, educacional, cultural, histórica e social, como canta Humberto Teixeira e Cícero Nunes 'Eu fui feliz lá no Bodocongó, com meu barquinho de um remo só'. No caso, de persistir a degradação, o Açude de Bodocongó tornar-se-á apenas uma página da história.

Projetos em Educação Ambiental implantados nos diversos níveis e modalidades de ensino, segundo os princípios e as diretrizes elencadas em documentos nacionais e internacionais são indispensáveis para provocar mudanças positivas no cenário que atualmente aflige o belo e histórico Açude de Bodocongó.

\section{REFERÊNCIAS}

ANTONI, R.; FOFONKA, L.. Impactos ambientais negativos na sociedade contemporânea. Educação Ambiental em Ação, v.12, n.45, 2013.
ANDRADE, L. R. S.; ARAÚJO, S. M. S.; ANDRADE, M. Z. S. S. MEDEIROS, E. L.. Degradação ambiental do açude de 
Bodocongó na cidade de Campina Grande, Paraíba. Revista verde de agroecologia e desenvolvimento sustentável, Pombal, v.13, n.1, p.74-83, 2018.

BRASIL. Conselho Nacional do Meio Ambiente. Resolução Conama n. 001 de 23 de janeiro de 1986 que estabelece critérios básicos e diretrizes gerais para a avaliação de impacto ambiental. Brasília: Ministério do Meio Ambiente, 1986.

BRASIL. Conselho Nacional do Meio Ambiente. Resolução $\mathbf{n}$. $\mathbf{2 7 4}$ de $\mathbf{2 9}$ de novembro de $\mathbf{2 0 0 0}$ que estabelece critérios de balneabilidade em águas brasileiras. Brasília: Ministério do Meio Ambiente, 2000.

BRASIL. Lei $\mathbf{n} . \mathbf{1 0 . 9 3 2}$ de 03 de agosto de 2004 que dispõe sobre loteamentos urbanos. Brasília: DOU, 2004.

BRASIL. Lei n. 12.651 de 25 de maio de 2012: Código

Florestal Brasileiro. Brasília: DOU, 2012.

BRÜGGER, P.. Educação ou adestramento ambiental?. 2 ed. Florianópolis: Letras Contemporâneas, 1999.

CAMPINA GRANDE. Lei complementar n. 042, de 24 de setembro de 2009 estabelece o Código de Defesa do Meio Ambiente. Campina Grande: DOE, 2009.

CARVALHO, A. P.. Diagnóstico da degradação ambiental do açude Bodocongó em Campina Grande-PB. Dissertação (Mestrado em engenharia agrícola) - Universidade Federal de Campina Grande, Campina Grande, 2007.

CARVALHO, A. P.; LIMA, V. L. A.; SILVA, D. G. K. C.; CARVALHO FILHO, A. M.. Determinação do índice de balneabilidade do açude em Campina Grande-PB, Brasil, a partir de indicadores biológicos. Revista Educação Ambiental em Ação, v.8, n.28, 2009.

COELHO, M. C. N.. Impactos ambientais em áreas urbanas: teorias, conceitos e métodos de pesquisa. In: GUERRA, A. J. T.; CUNHA, S. B.. Impactos Ambientais Urbanos no Brasil. 2 ed. Rio de Janeiro: Bertrand Brasil, 2004.

COSTA, T. C. F.. Ações antrópicas de impactos negativos no açude de Bodocongó no município de Campina Grande, Paraíba. Revista Brasileira de Informações Científicas, v.2, n.2, p.78-89, 2011.

CPRM. Serviço Geológico do Brasil. Projeto cadastro de fontes de abastecimento por água subterrânea. Diagnóstico do município de Campina Grande, estado da Paraíba. Recife: CPRM/PRODEEM, 2005.

DAMAME, D. B.; OLIVEIRA, E. D.; LONGO, R. M.. Impactos ambientais pelo uso e ocupação do solo em sub bacias hidrográficas de Campinas, São Paulo, Brasil. Acta Brasiliensis, v.3, n.1, p.1-7, 2019.

ESTEVES, F. A.. Fundamentos de Limnologia. 2 ed. Rio de Janeiro: Interciência, 1998.

FERREIRA, A. M.; MORAES NETO, J. M.; ARAGÃO, K. P..
Estudo da degradação ambiental da bacia hidráulica do Açude de Bodocongó. Revista Educação Agrícola Superior, v.29, n.2, p.81-84, 2014.

GUEDES FILHO, D. H.; FERNANDES NETO, S.; SANTOS JÚNIOR, J. A.; SUASSUNA, J. F.; BARACUHY, J. G. V.. Uso e ocupação nas margens do Açude Bodocongó/PB. Revista Educação Agrícola Superior, v.27, n.1, p.70-75, 2012. DOI: http://doi.org/10.12722/0101-756X.v27n01a12

IBGE. Instituto Brasileiro de Geografia e Estatística. População estimada para Campina Grande. Brasília: Ministérios do Meio Ambiente, 2019.

MACHADO, L. M. C. P.. A percepção do meio ambiente como suporte para a educação ambiental. In: POMPÊO, M. L. M.. Perspectivas na Limnologia no Brasil. União, 1999. p.113.

MELO, W. J.; MELO, G. M. P.; MELO, V. P.; LONGO, R. M.; RIBEIRO, A. I.; BERTIPAGLIA, L. M. A.. Manejo de solos degradados por ação antrópica. In: ROSA, A. H.; FRACETO, L. F.; CARLOS, V. M.. Meio ambiente e sustentabilidade. Porto Alegre: Bookman, 2012. p.412.

MORAES NETO, J. M.; VASCONCELOS, L. M. S. X.; FERNANDES, M. F.; SILVA, M. J.. Estudo dos riscos a desastres no entorno do açude de Bodocongó. In: CONGRESSO TÉCNICO CIENTÍFICO DA ENGENHARIA E DA AGRONOMIA, 73. Anais. Foz do Iguaçu: CONTECC, 2016.

ROCHA, J. S. M.. Manual de projetos ambientais. Santa Maria: Universidade Federal de Santa Maria, 1997.

SÁNCHEZ, L. E.. Avaliação de impacto ambiental: conceitos e métodos. São Paulo: oficina de textos, 2008.

SILVA, G. L. M.; SILVA, D. P. L.; SILVA, S. P.. Avaliação dos impactos ambientais negativos ocorridos nas nascentes do Rio Grunga: estudo de caso no município de Senhor do Bonfim-BA. In: CONGRESSO BRASILEIRO DE GESTÃO AMBIENTAL, 4. Anais. Salvador: CONGEA, 2013.

SILVA, M. M. P.. Manual de educação ambiental: uma contribuição à formação de agentes multiplicadores em educação ambiental. Curitiba: Appris, 2020.

SILVA, M. M. P.; LEITE, V. D.. Análise da percepção ambiental de educandos do ensino fundamental em escolas públicas municipais da cidade de Campina Grande-PB. In: CONGRESSO INTERAMERICANO DE ENGENHARIA SANITÁRIA E AMBIENTAL, 27. Anais. Porto Alegre: Abes, 2000.

SILVA, M. M. P.; LEITE, V. D.. Percepção da relação ser humano e meio ambiente de educadores do ensino fundamental da cidade de Campina Grande/PB. In: CONGRESSO BRASILEIRO DE ENGENHARIA SANITÁRIA E AMBIENTAL, 21. Anais. João Pessoa: Abes, 2001.

SILVA, M. M. P.; LEITE, V. D.; ROSA, L. G.; VIEIRA, M. M. P.; SOUZA, J. M. F.; ANDRADE, L. A.. Percepção ambiental de educadores e educadoras do estado da Paraíba/Brasil. In CONGRESSO INTERAMERICANO INGENIERIA SANITARIA Y AMBIENTAL, 28. Anais. Cancún: Abes, 2002.

A CBPC - Companhia Brasileira de Produção Científica (CNPJ: 11.221.422/0001-03) detém os direitos materiais desta publicação. Os direitos referem-se à publicação do trabalho em qualquer parte do mundo, incluindo os direitos às renovações, expansões e disseminações da contribuição, bem como outros direitos subsidiários. Todos os trabalhos publicados eletronicamente poderão posteriormente ser publicados em coletâneas impressas sob coordenação da Sustenere Publishing, da Companhia Brasileira de Produção Científica e seus parceiros autorizados. Os (as) autores (as) preservam os direitos autorais, mas não têm permissão para a publicação da contribuição em outro meio, impresso ou digital, em português ou em tradução. 